\title{
Correction to: RETRACTED ARTICLE: Studying fractal geometry of structural physical properties of PVDF/graphene: mechanical reinforcement and electrical conductivity
}

Hamid Sarkheil $^{1} \cdot$ Shahrokh Rahbari ${ }^{1}$

Published online: 3 September 2018

(c) Springer Nature Switzerland AG 2018

Correction to: Graphene Technol (2017) 2:41

https://doi.org/10.1007/s41127-017-0004-7

The authors do not agree to the retraction of this article [1]. In addition to the overlap with Lopes and Betrouni, this article was retracted due to overlap with a number of other sources.

References:

1. Original article/retraction notice (https://doi.org/10. 1007/s41127-017-0004-7)

The original article can be found online at https:// doi.org/10.1007/s41127-017-0004-7.

\section{Hamid Sarkheil}

sarkheil_h@yahoo.co.uk

1 College of Environment, Karaj, Alborz, Islamic Republic of Iran 